\title{
Spinal intradural teratomas: developmental programs gone awry?
}

\author{
*M. Yashar S. Kalani, M.D., Ph.D., ${ }^{1}$ Sudarshan Iyer, ${ }^{1}$ Stephen W. Coons, M.D., ${ }^{2}$ \\ and Kris A. SMith, M.D. ${ }^{1}$ \\ ${ }^{1}$ Division of Neurological Surgery, and ${ }^{2}$ Division of Neuropathology, Barrow Neurological Institute, \\ Phoenix, Arizona
}

Intradural spinal teratomas are rare tumors of the spinal cord that are infrequently encountered in children. Although the mechanistic basis for the formation of these tumors is unclear, several lines of evidence suggest that a dysembryogenic process in the embryo results in their formation. The authors present a case of spinal intradural teratoma in an 18-year-old, previously healthy man and review the literature linking the development of these tumors to defects in neurulation and embryogenesis.

(http://thejns.org/doi/abs/10.3171/2012.8.FOCUS12230)

Key Words - spinal teratoma - neural tube defect • dysraphism

$\mathrm{T}$ ERATOMAS are growths that consist of all 3 embryonic tissue types: endoderm, mesoderm, and ectoderm. ${ }^{1,2,9}$ Spinal teratomas are exceedingly rare and constitute $0.1 \%-0.5 \%$ of all spinal tumors. ${ }^{2,9,10}$ Intradural spinal teratomas can be located either extra- or intramedullary, ${ }^{1,4,8-10}$ and can be classified as mature or immature based on the degree of differentiation. , $^{1,4,9,10}$ Whereas the classic model posits that spinal teratomas are the result of misplaced primordial germ cells, an alternative theory suggests that a dysembryogenic mechanism may be at the root of these lesions. The proponents of the dysembryogenic theory cite the association of these lesions with dysraphic malformations, the pluripotent nature of the developing caudal spinal cord, and evidence for dysembryogenic origin in other midline tumors as substantiation for this mechanism. ${ }^{1,7,9,12}$ We present a case of intradural spinal teratoma in an 18-year-old man with symptoms of bilateral lower-extremity weakness, and we review the literature regarding theories on the origin of spinal teratomas.

\section{Case Report}

History and Examination. This previously healthy 18-year-old man presented to the emergency department with bilateral proximal lower-extremity weakness (Grade $3-4 / 5)$. Examination of the lower extremity revealed hyperreflexia and diminished sensation. The patient had

\footnotetext{
Abbreviations used in this paper: $\mathrm{OR}=$ operating room; $\mathrm{SCM}=$ split cord malformation.

* Dr. Kalani and Mr. Iyer contributed equally to this work.
}

been treated with traditional Native American remedies without improvement of symptoms, and 10 days previously a spinal steroid injection had been administered in the midthorax, which caused a rapid decline in his motor strength. Neuroimaging revealed a large intradural mass at the T-10 level with compression of the spinal cord (Fig. 1). The lesion was contrast enhancing (Fig. 1B) at its periphery and appeared to displace the spinal cord to the left (Fig. 1D). The T2-weighted sequences suggested that the mass was cystic (Fig. 1C and D). Given the patient's symptoms, the patient was immediately taken to the OR for urgent decompression and resection of the mass.

Operation and Pathological Findings. The patient underwent a T-10 laminoplasty and microsurgical resection of the tumor. Intraoperatively, the tumor was noted to be intradural and adherent to the spinal cord and nerve roots. The tumor was fibrous in nature with fatty elements and a large cystic component. The contents of the cyst appeared mucinous in color and consistency. Intraoperatively, a frozen section was sent for pathological evaluation. Frozen pathology was consistent with spindle cell tumor, with a likely diagnosis of neurofibroma. Given the benign nature of the diagnosis and the adherent nature of the tumor to the spinal cord, we elected to decompress the spinal cord and not pursue a gross-total resection. Postoperatively the patient was neurologically stable.

Pathological investigation revealed a mature spinal teratoma with cartilaginous (Fig. 2A), pulmonary (Fig. 2B), and muscular (Fig. 2C) differentiation. Postoperative imaging revealed subtotal resection of the tumor with interval decompression of the spinal cord (Fig. 3A and B). 


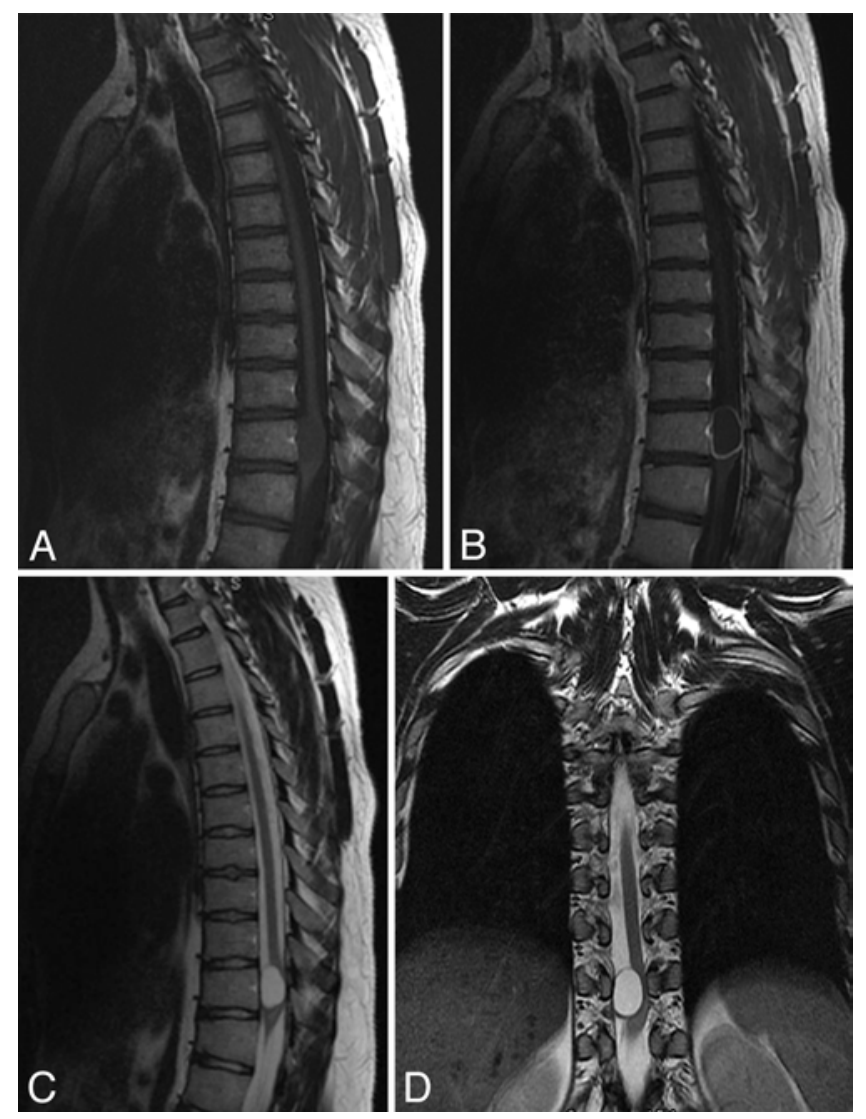

FIG. 1. Sagittal precontrast (A) and postcontrast (B) T1-weighted MRI sequences revealing an intradural ventrally located mass compressing the spinal cord at the T-10 level. The lesion enhances at its periphery after contrast administration $(B)$, and is noted to be cystic on the T2-weighted sequences ( $C$ and $D$ ).

Given the lack of clear guidelines on the management of these lesions and the goal of not subjecting the patient to irradiation, we elected to return to the OR with planned complete resection of the lesion. The second stage of resection was achieved without complication and the patient was neurologically stable postoperatively. Postoperative imaging revealed near-total resection of the tumor, with a small amount of residual lesion densely adherent to the spinal cord (Fig. 3C and D). The dense fibrous tumor cyst capsule also appeared to be connected and essentially
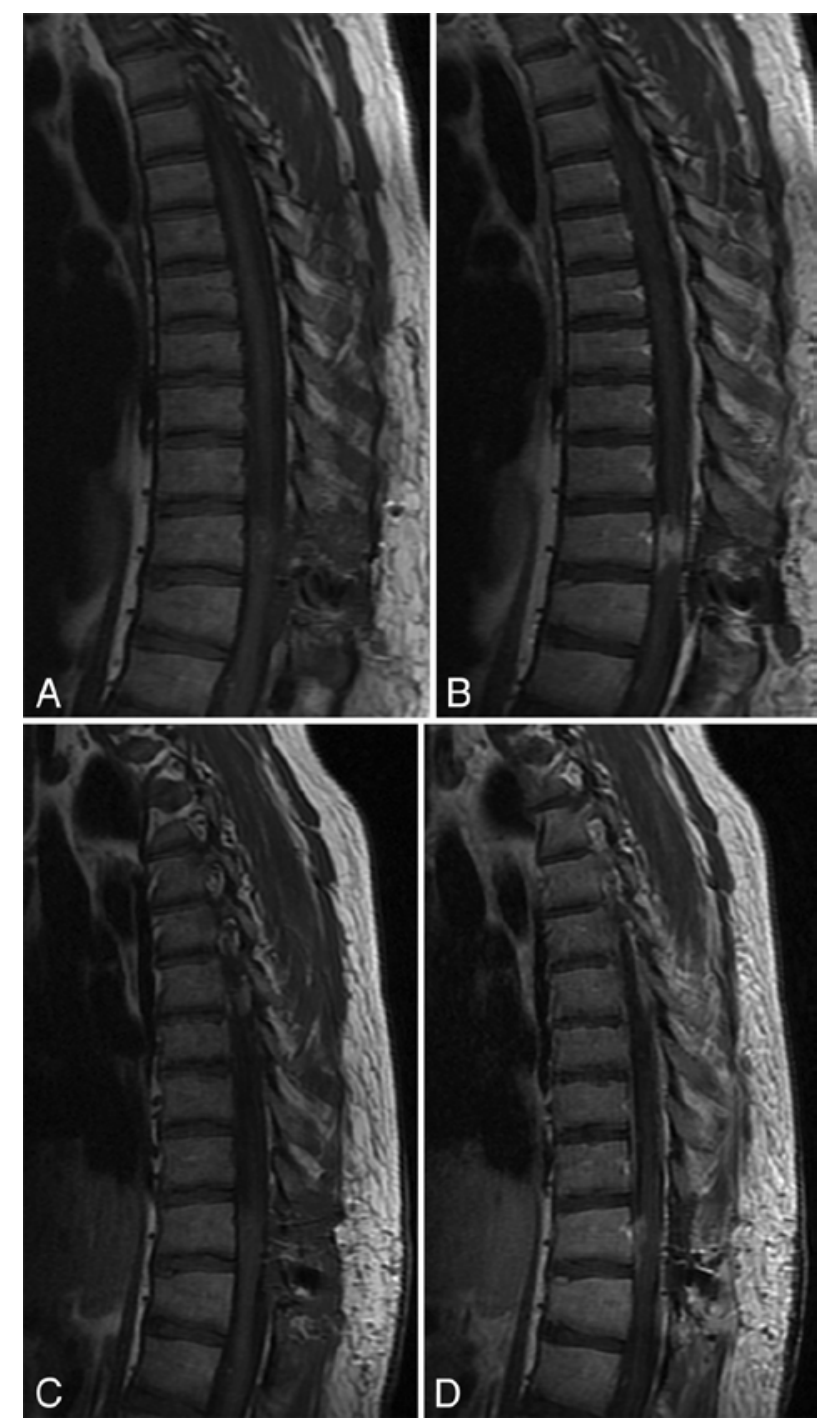

FIG. 3. The patient was taken to the $O R$ for a staged operation. After the first operation, sagittal precontrast (A) and postcontrast (B) T1-weighted MRI sequences revealed a rim of residual tumor adherent to the spinal cord. The patient was then taken to the OR for a more aggressive resection. After the second operation, sagittal precontrast (C) and postcontrast (D) T1-weighted MRI sequences revealed a neartotal resection of the tumor, with minimal residual lesion adherent to the spinal cord.
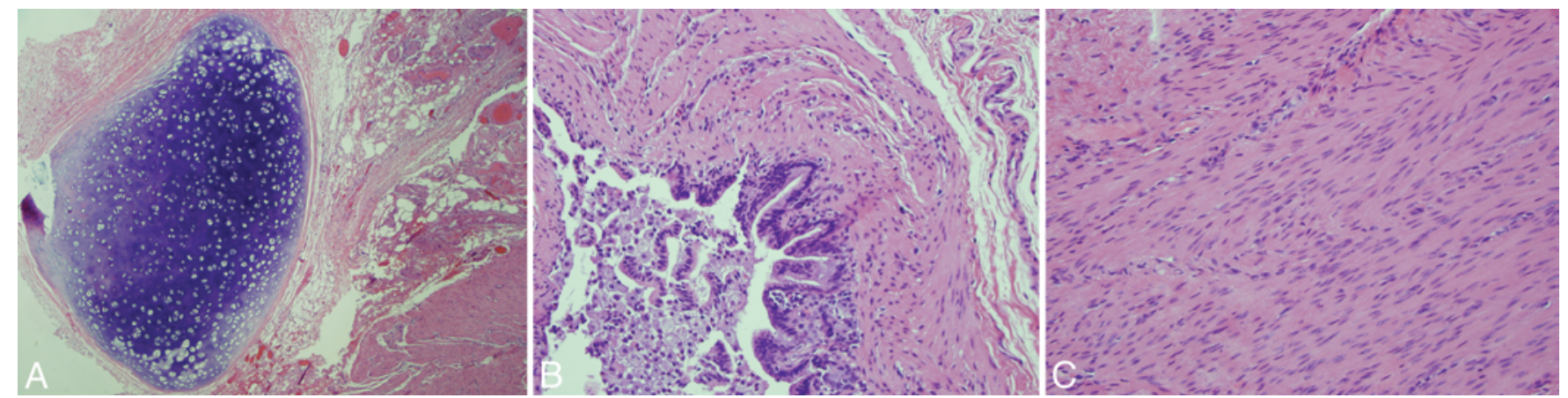

FIG. 2. Pathological studies of this lesion revealing a teratoma. Photomicrographs of tumor sections showing cartilaginous (A), pulmonary glandular tissue (B), and muscular (C) differentiation. H \& E, original magnification $\times 40(A)$ and $\times 200$ (B and C). 
contiguous with the dura mater into a ventral defect in the dural lining of the thecal sac.

Postoperative Course. After review of the patient's records with our oncology and radiation oncology colleagues, we elected to follow him expectantly and not pursue further treatment at this time. Three months postoperatively, the patient has improved strength and sensation without evidence of recurrent disease.

\section{Discussion}

Teratomas are lesions consisting of all 3 developmental germ layers. ${ }^{9}$ In the spine, teratomas make up only $0.1 \%-0.5 \%$ of all tumors. ${ }^{3,10}$ The first treatment of an intradural spinal teratoma has been attributed to Virchow, who, in 1863, described a mass containing connective tissue, fat, and cartilage. ${ }^{\text {? }}$

The mechanisms behind the formation of teratomas are unclear. The traditional theory of pathogenesis centers on the misplacement of primordial, pluripotent germ cells from the primitive yolk sac early during embryogenesis. ${ }^{1,7}$ The most frequent location for misplacement of these early germ cells is in the dorsal midline in the migration from the yolk sac to the gonadal ridges. ${ }^{7,10}$ In support of this theory, the nuclei of some teratomas from male patients have been shown to contain female sex chromatin bodies, suggesting that the origin of the teratoma may be from primordial germ cells that had not yet entered into the first division in meiosis. ${ }^{1}$ Opponents of this theory cite the possibility of mosaicism or XO karyotype of a population of cells as the source of this finding. ${ }^{7}$

An alternative to the germ cell theory proposes that a dysembryogenic mechanism facilitates the creation of intradural spinal teratomas. Three pieces of evidence serve to promote this line of thinking, as follows.

\section{1) Dysraphic Features Associated With Intradural Spinal Teratomas}

Many intradural spinal teratomas present with associated dysraphic features associated with them. In a series of 27 intradural spinal teratomas, Sharma et al. ${ }^{9}$ noted that $77.7 \%$ of the tumors had a concomitant dysraphism such as SCM, tethered cord, spina bifida, and meningomyelocele. It is suggested that teratomas and the associated dysraphic features are the result of a single developmental process.?

Several interesting cases of intradural spinal teratoma associated with dysraphic features have been published in recent years. Jain et al. ${ }^{5,6}$ have published 3 cases of intradural spinal teratoma associated with SCM. One of the cases featured an intradural spinal teratoma with an SCM Type I at L-2, left hemicord lipoma, right hemicord meningocele, and a small dermoid at L-1; the teratoma in this particular case was found to have pulmonary differentiation, with bronchial structures containing pseudostratified ciliated epithelium along with bronchioles and alveoli. ${ }^{5}$ The other 2 cases featured intradural spinal teratomas, with one patient having an SCM Type I at L-2 and the other an SCM Type II at L-3 with spina bifida at L2-4. These 2 teratomas contained mature, ectopic renal tissue, with both having glomeruli and tubules. ${ }^{6}$ The au- thors postulate that neural tube defects interfere with the migration of renal tissue during embryogenesis, explaining the renal differentiation seen in the teratoma. Uzüm et al. ${ }^{11}$ also report a case of intradural spinal teratoma with SCM, tethered cord, and immature nephroblastic tissue.

It is interesting to note that a group of intradural spinal teratomas do not have associated dysraphic features. In the series published by Sharma et al., ${ }^{9} 22.2 \%$ of intradural spinal teratomas lacked dysraphic features. Al-Sarraj et al. ${ }^{1}$ did not identify dysraphisms in $57 \%$ of cases in their series. In our case, we did not identify obvious dysraphic features; however, a slight dural defect ventrally was suspected in surgery but was not visible on imaging. Regardless, clearly a subset of spinal teratomas is not associated with dysraphisms.

\section{2) Pluripotent Nature of Developing Caudal Spinal Cord}

Although a local dysembryogenic process would help to explain the many dysraphic features associated with intradural spinal teratoma, it does not explain why teratomas form. The caudal spinal cord in the developing embryo is known to contain a population of undifferentiated mesenchymal stem cells. These mesenchymal progenitor cells have been shown to give rise to teratomas when transplanted into developing embryos. ${ }^{7}$ It is well known that the developing neural tube and adjacent somites establish signaling centers that guide the differentiation of adjacent tissues. Disruption of signaling centers can affect the migration and patterning of progenitor cells, resulting in their retention and the formation of teratomas. ${ }^{7,9}$ When combined with the presence of dysraphic features, this theory proposes that during the process of neurulation, alterations in the developmental processes result in dysraphisms and in the activation, retention, and growth of pluripotent cells, resulting in the formation of teratomas.

\section{3) Dysembryogenic/Prenatal Origin Proposed for Other Midline Neoplasms}

The theory that intradural spinal teratomas form due to a dysembryogenic mechanism finds support in the formation of other midline neoplasms. The split notochord syndrome is characterized by a fistula between the yolk sac and the amniotic cavity caused by partial duplication and separation of the notochord during embryogenesis; the fistula closes due to further development of the embryo, and remnants of the yolk sac then differentiate into tissues related to the gut. ${ }^{12}$ This process is thought to give rise to the formation of enterogenous cysts. Proponents of the dysembryogenic theory cite similarities in the formation of this and other midline masses as evidence for the malfunction of existing developmental programs as the basis of teratomas.

\section{Conclusions}

The pathogenesis of teratomas in general and spinal teratomas in particular is unclear. The evidence in support of both predominant theories for the formation of these lesions is marginal at best. These lesions continue 
to fascinate us and call into question our understanding of the development of the nervous system. With unclear guidelines for their treatment and association with dysraphisms, we recommend aggressive resection of these lesions, close follow-up in case of recurrence, and a search for other developmental defects in these patients. Adjuvant radiation was not used in our patient and is not likely to be necessary, given the lack of cellular proliferation and the benign nature of the pathological entity. This strategy avoids potential long-term radiation toxicity or delayed radiation-induced malignant degeneration. However, follow-up with sequential imaging is necessary in light of some residual cyst wall.

\section{Disclosure}

The authors report no conflict of interest concerning the materials or methods used in this study or the findings specified in this paper.

Author contributions to the study and manuscript preparation include the following. Conception and design: Smith, Kalani. Acquisition of data: Kalani, Iyer, Coons. Analysis and interpretation of data: all authors. Drafting the article: Kalani, Iyer. Critically revising the article: Smith, Kalani. Reviewed submitted version of manuscript: Smith, Kalani. Approved the final version of the manuscript on behalf of all authors: Smith. Study supervision: Smith, Coons.

\section{References}

1. al-Sarraj ST, Parmar D, Dean AF, Phookun G, Bridges LR: Clinicopathological study of seven cases of spinal cord teratoma: a possible germ cell origin. Histopathology 32:51-56, 1998

2. Basmaci M, Hasturk AE, Pak I: Cystic mature teratoma of the thoracic region in a child: an unusual case. J Neurosci Rural Pract 2:186-189, 2011

3. Borlot F, Soares MS, Espíndola AA, Reed UC, Matushita H, Teixeira MJ: Intramedullary spinal teratoma: a rare condition with a good outcome. Arq Neuropsiquiatr 67:733-735, 2009
4. Ishiguro S, Nagashima T, Yamamoto K, Kanekawa K, Yoshida M, Kondoh T: An infantile large and extensive intramedullary mature spinal teratoma. Neurol Med Chir (Tokyo) 51: 393-396, 2011

5. Jain D, Sharma MC, Sarkar C, Rishi A, Suri V, Garg A, et al: Spinal teratoma with pulmonary differentiation: a report of rare case and review of literature. Fetal Pediatr Pathol 26: 185-191, 2007

6. Jain D, Sharma MC, Sarkar C, Rishi A, Suri V, Garg A, et al: Spinal teratoma with renal differentiation-a rare phenomenon: report of two patients. Clin Neurol Neurosurg 110: 265-269, 2008

7. Koen JL, McLendon RE, George TM: Intradural spinal teratoma: evidence for a dysembryogenic origin. Report of four cases. J Neurosurg 89:844-851, 1998

8. Park SC, Kim KJ, Wang KC, Choe G, Kim HJ: Spinal epidural teratoma: review of spinal teratoma with consideration on the pathogenesis: case report. Neurosurgery 67:E1818-E1825, 2010

9. Sharma MC, Jain D, Sarkar C, Suri V, Garg A, Singh M, et al: Spinal teratomas: a clinico-pathological study of 27 patients. Acta Neurochir (Wien) 151:245-252, 2009

10. Sung KS, Sung SK, Choi HJ, Song YJ: Spinal intradural extramedullary mature cystic teratoma in an adult. J Korean Neurosurg Soc 44:334-337, 2008

11. Uzüm N, Dursun A, Baykaner K, Kurt G: Split-cord malformation and tethered cord associated with immature teratoma. Childs Nerv Syst 21:77-80, 2005

12. Yamashita J, Maloney AF, Harris P: Intradural spinal bronchiogenic cyst. Case report. J Neurosurg 39:240-245, 1973

Manuscript submitted June 15, 2012.

Accepted August 7, 2012.

Please include this information when citing this paper: DOI: 10.3171/2012.8.FOCUS12230.

Address correspondence to: Kris A. Smith, M.D., Neuroscience Publications, Barrow Neurological Institute, 350 West Thomas Road, Phoenix, Arizona 85013-4496. email: neuropub@chw.edu. 